\title{
FONTES ALTERNATIVAS E RENOVÁVEIS DE ENERGIA NO BRASIL: MÉTODOS E BENEFÍCIOS AMBIENTAIS
}

\section{Raphael Santos do Nascimento ${ }^{1}$ \\ Geziele Mucio Alves ${ }^{2}$}

\begin{abstract}
Resumo: Atualmente, os recursos renováveis tem sido o foco de inúmeras pesquisas, devido à preocupação com o meio ambiente. Nesse sentido, várias são as razões para a implementação de fontes renováveis de energia. Assim, o objetivo desse estudo foi identificar os diferentes tipos de energias renováveis existentes no Brasil, bem como, a aplicabilidade e o impacto ambiental gerado por essas fontes. O trabalho foi desenvolvido sobre os preceitos do estudo exploratório por meio de uma pesquisa bibliográfica. Foram identificados cinco tipos de energias alternativas renováveis no Brasil, Biomassa, Eólica, Geotérmica, Hidráulica, Marítima e Solar. A energia Solar foi considerada a mais viável em função de sua aplicabilidade, mesmo em locais isolados, do potencial encontrado em todo território, e, a redução dos impactos ambientais. Foram consideradas expressivas as diferenças de impacto ambiental entre as fontes estudadas e as fontes não-renováveis. Ainda, identificou-se que mesmo com diversas alternativas energéticas e um imenso potencial de recursos renováveis, a utilização desses recursos no Brasil deve ser considerada insuficiente para geração de energia.
\end{abstract}

Palavras-chave: Fontes alternativas; Energias renováveis; Impactos ambientais.

\footnotetext{
${ }^{1}$ Engenharia Elétrica/Centro Universitário Ingá - UNINGÁ, Brasil. E-mail: raphael_caixa@hotmail.com.

2 Biologia/Universidade Estadual de Maringá - UEM, Brasil. E-mail: geziele.alves@gmail.com.
} 